\title{
The Evaluation of Wnt Pathway Proteins (Wnt-1/B-Catenin/ E-Cadherin) in Bone Marrow Biopsies in Essential Thrombocythemia and Polycythemia Vera
}

\author{
Hatice Kucuk (Corresponding author) \\ Trabzon Kanuni Training and Research Hospital \\ Department of Pathology, 61080 Trabzon, Turkey \\ E-mail: dr.hatice.kucuk@hotmail.com \\ Umit Cobanoglu \\ Karadeniz Technical University Faculty of Medicine, \\ Department of Pathology, 61080 Trabzon, Turkey \\ E-mail: drumitcoban@ktu.edu.tr \\ Mehmet Sonmez \\ Karadeniz Technical University Faculty of Medicine, \\ Department of Hematology, 61080 Trabzon, Turkey \\ E-mail: mesonmez@yahoo.com
}

\begin{abstract}
The aim of the study is to investigate the expressions of Wnt signal pathway proteins (Wnt-1/BCatenin/E-Cadherin) in polycythemia vera and essential thrombocythemia. In addition to 25 Polycythemia vera and 25 Essential thrombocytosis cases who received bone marrow biopsies with the diagnoses of Polycythemia vera and Essential thrombocytosis, 25 normocellular bone marrow biopsies were included as the control group. In cells belonging to erythroid, myeloid and megakaryocytic series in the bone marrow biopsies of the cases, Wnt-1, $\beta$-catenin and E-cadherin expressions were examined by the immunohistochemical method. For each series, staining up to $10 \%$ was accepted as negative, and $10 \%$ and higher staining was accepted as positive. In the Essential thrombocytosis cases, there was a significant increase in the Wnt-1 expression in the megakaryocytic series and E-cadherin expression in the erythroid series $(p<0.05)$. When the cases were assessed within themselves based on the three series, an increase in E-cadherin and E-cadherin expression in the erythroid series in the Polycythemia vera cases and Wnt-1 expression in the megakaryocytic series in the Essential thrombocytosis cases was observed $(p<0.05)$. $\beta$-catenin expression was not encountered in the cases. Consequently, it was considered that Wnt-1 may be associated with megakaryocytopoiesis in ET cases, and E-cadherin may be associated with erythropoiesis in ET cases. However, it will be beneficial to repeat the study on broader myeloproliferative neoplasm series and assess other factors in the Wnt pathway.
\end{abstract}

Keywords: Essential Thrombocytosis, Polycythemia Vera, Wnt-1, $\beta$-catenin, E-cadherin

DOI: $10.7176 / J S T R / 7-06-04$

\section{Introduction}

According to World Health Organization (WHO) classification, myeloproliferative neoplasms (MPN) are ivided into 7roups. PV and ET constitute 2 separate disease groups in this classification (Georgii et al. 1998; Swerdlow et al. 2008).

Polycythemia vera is a disease with an insidious onset that is characterized by excessred blood cells increasing independently of normal erythropoiesis mechanisms. In almost all patients, the JAK2 V617 somatic mutation in the JAK kinase gene leading to proliferation in not only the erythroid series but also the granulocytic and myeloid series is observed(Bloom and Bartelmez 1940; Kralovics et al. 2005; Swerdlow et al. 2008; Tsiftsoglou et al. 2009; Porwit et al. 2011).

33 | P a g e

www.iiste.org 
Essential thrombocytosis is among myeloproliferative neoplasms (Gianelli et al. 2006). The disease primarily concerns the megakaryocytic series. There is no known biological marker for the diagnosis of ET. There is a mutation in the JAK kinasegenein 40-50\%of cases(Murphy 1999; Ding et al. 2004; Kralovics et al. 2005; Levine et al. 2005; Gisslinger 2006; Swerdlow et al. 2008).

Wnt-1, Wnt-5a, Wnt-2b and Wnt-10b have been cloned from human fetal bone stromal cells(DALE 1998; Brandon et al. 2000). Although the effects of the Wnt signal pathway on the hematopoietic system are partially known, it also has a significant role in the development of various organs. During fetal hematopoiesis Wnt proteins, especially Wnt5a-Wnt-10 bare expressed in the yolk sac and the liver and in the embryo hematopoiesis takes place in both of these. The Wnt 3A protein is important in selfrenewal of hematopoietic stem cells. These genes play an important role in determining the fate of several types of cells during carcinogenesis and embryogenesis(Austin et al. 1997).

$\beta$-catenin is a cytoplasmic protein which is a component of the Wnt signal pathway. It has been found that the Wnt/ $\beta$-catenin pathway has a significant role in the self-renewal of stem cells in different tissues like the intestinal crypts, hair follicles and hematopoietic cells(Van Den Berg et al. 1998). Throughout the life of the individual hematopoietic stem cells are reconstructed through proliferation and differentiation. $\beta$-catenin has these two effects.

E-cadherin is found in the Wnt signal pathway. It is an important adhesion molecule that serves in a bond with calcium in the adhesion of cells to each other. It is found on the surfaces ofepithelialcells. It is an important tumor suppressor gene. The E-cadherin(ECAD) geneis localized at CDH116q22.1. Loss of the ECAD genele adsto loss of cellular adhesion, metastasis development and shortened lifespan. In addition to the sepathways, the bone marrow contains the $\mathrm{ScF} / \mathrm{c}$-kit signal pathway, Notch signal pathway, HOX signal pathway and EPO signal pathway (Brandon et al. 2000; Domen and Weissman 2000).

The aim of the study is to investigate the expressions of Wnt signal pathway proteins (Wnt-1/BCatenin/E-Cadherin) in polycythemia vera and essential thrombocythemia.

\section{Materyal Metod}

Twenty-five PV and 25 ET cases who received bone marrow biopsy with the diagnoses of PV and ET at the Department of Hematology at the Karadeniz Technical University School of Medicine, as well as 25 normocellular bone marrow biopsies as the control group, were included in the study The present study followed the Declaration of Helsinki for medical protocols and ethics. The Karadeniz Technical University Institutional Review Board approved the study plan under protocol 2011/4.

\subsection{Immunohistochemical assessment}

The paraffin blocks and slides of the cases were taken out of the archive of the pathology department. The H\&E-stained slides were reevaluated and the suitable paraffin blocks were selected. For immunohistochemical staining, three 5-micron-thick cross-sections were taken out of each paraffin block on to adhesive-coated glasses. From the paraffin blocks of each case 3cross-sections were prepared to study Wnt-1, E-cadherin and, $\beta$-catenin.

At the next stage, all staining steps including deparfinization and antigen release were facilitated by using a Benchmark XT automated immunohistochemistry staining device. The antigenic staining procedure was carried out with a peroxidase-labeled Streptavidin-biotin kit and diaminobenzidine chromogen. Mayer's Hematoxylin was used for surface staining. As the positive control group, breast invasive ductal carcinoma tissue was used for immunohistochemical markers. The slides were assessed by the same single observer. In the immunohistochemical assessment, for all three antibodies, assessment was made to include 2000 cells in the erythroid, myeloid and at least 20 megakaryocytes. In the assessment, for each series, staining upto $10 \%$ was considered negative, while staining of $10 \%$ or more was considered positive.

\subsection{Statistical analysis}

All cases were subjected to statistical analysis by comparison based on theWnt-1, Beta-catenin and E-cadherin antibodies and expression characteristics. The statistical analyses were carried out at the Department of Public Health at the Karadeniz Technical University School of Medicine. Chisquared test was used to compare the qualitative data. The data obtained by counting are expressed in $\%$. 


\section{Results}

Among the total of 75 cases included in the study, 25 were PV cases (Figure 1), 25 were ET cases (Figure 2), and 25 were the control group. Among the PV cases, $12(48 \%)$ were female and 13(52\%) were male, among the ET cases,16(64\%) were female and 9(36\%) were male and among the control cases, $15(60 \%)$ were female, and $10(40 \%)$ were male. The age distribution of the PV cases was as 2979 (mean: 57.48), that of the ET cases was as 23-80(mean: 47.92), and that of the control group was as 25-72 (mean: 47.44). With Wnt, staining was observed in the megakaryocytic series in1 PV case. No positive result was observed in the myeloid and erythroid series. With E-cadherin, positive results were obtained in the erythroid series in 6 PV cases and in the megakaryocytic series in 1 PV case. No positive result was observed in the myeloid series. With $\beta$-catenin, no positive result was observed in the PV cases.

With Wnt, positive results were observed in the megakaryocytic series in 6 ET cases (Figure3). No positive result was observed in the erythroid and myeloid series. With E-cadherin, positive results were observed in the erythroid series in 12 ET cases (Figure 4). No positive result was observed in the myeloid and megakaryocytic series. With $\beta$-catenin, no positive result was found in the ET cases.

With Wnt, positive results were obtained in the megakaryocytic series in 2 of the control cases. No positive result was observed in the erythroid and myeloid series. With E-cadherin, a positive result was observed in the erythroid series in1 control case. No positive result was observed in the megakaryocytic and myeloid series. There was no positive result in the control group cases with $\beta$-catenin. Table I presents PV, ET and control group cases with Wnt-1, $\beta$-catenin and E-cadherin expressions.

In the comparison of the ET, PV and control group cases with $\beta$-catenin and the immunohistochemical expression results, no significant result could be obtained $(p>0.05)$. However, in the comparison of the ET, PV and control group cases withWnt-land the immunohistochemical expression results, in the megakaryocytic series, $24 \%$ positive results in the ET cases, a $4 \%$ positive result in the PV cases and a $4 \%$ positive result in the control cases were obtained. In the ET cases, there was a significant difference in terms of the Wnt-1expression in the megakaryocytic series $(p<0.05)$. In the comparison of E-cadherin and the immunohistochemical expression results, in the erythroid series, $48 \%$ positive results in the ET cases, $24 \%$ positive results in the PV cases and a $4 \%$ positive result in the control cases were observed. In the ET cases, there was a significant difference in terms of the E-cadherin expression in the erythroid series $(p<0.05)$. In the control group, a $4 \%$ positive result was obtained with E-cadherin in the erythroid series. No significant difference was determined $(\mathrm{p}>0.05)$.

Table I: Immunohistochemical findings of the ET, PV and control groups.

\begin{tabular}{|l|c|c|c|c|c|c|c|c|c|}
\hline Case & \multicolumn{3}{|l|}{ Wnt-1(n) } & \multicolumn{3}{l|}{ E-cadherin(n) } & \multicolumn{3}{l|}{$\beta$-catenin(n) } \\
\hline PV (n:25) & ER & MY & MG & ER & MY & MG & ER & MY & MG \\
\hline Negative & 25 & 25 & 24 & 19 & 25 & 24 & 25 & 25 & 25 \\
\hline Positive & 0 & 0 & 1 & 6 & 0 & 1 & 0 & 0 & 0 \\
\hline ET (n:25) & & & & & & & & & \\
\hline Negative & 25 & 25 & 19 & 13 & 25 & 25 & 25 & 25 & 25 \\
\hline Positive & 0 & 0 & 6 & 12 & 0 & 0 & 0 & 0 & 0 \\
\hline Control(n:25) & & & & & & & & & \\
\hline Negative & 25 & 25 & 23 & 24 & 25 & 25 & 25 & 25 & 25 \\
\hline Positive & 0 & 0 & 2 & 1 & 0 & 0 & 0 & 0 & 0 \\
\hline
\end{tabular}

Abbreviations. PV: Policytemavera, ET: Essential thrombocytemia, ER: Erythroid lineage , MY: Myeloid lineage, MG: Megacaryocytes 


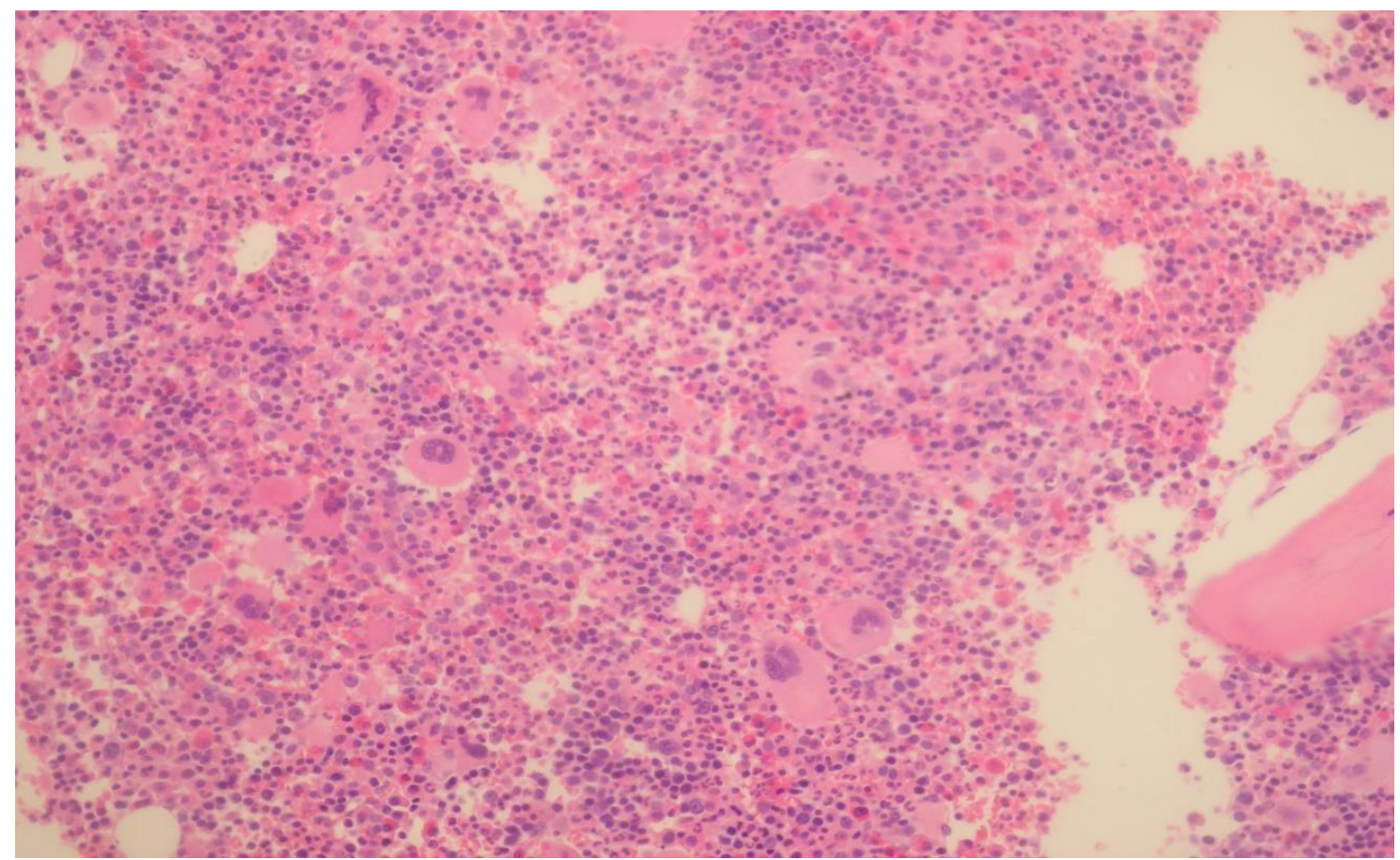

Figure 1: Trilineage hyperplasia in a case of polycythemia vera (H\&E; x100).

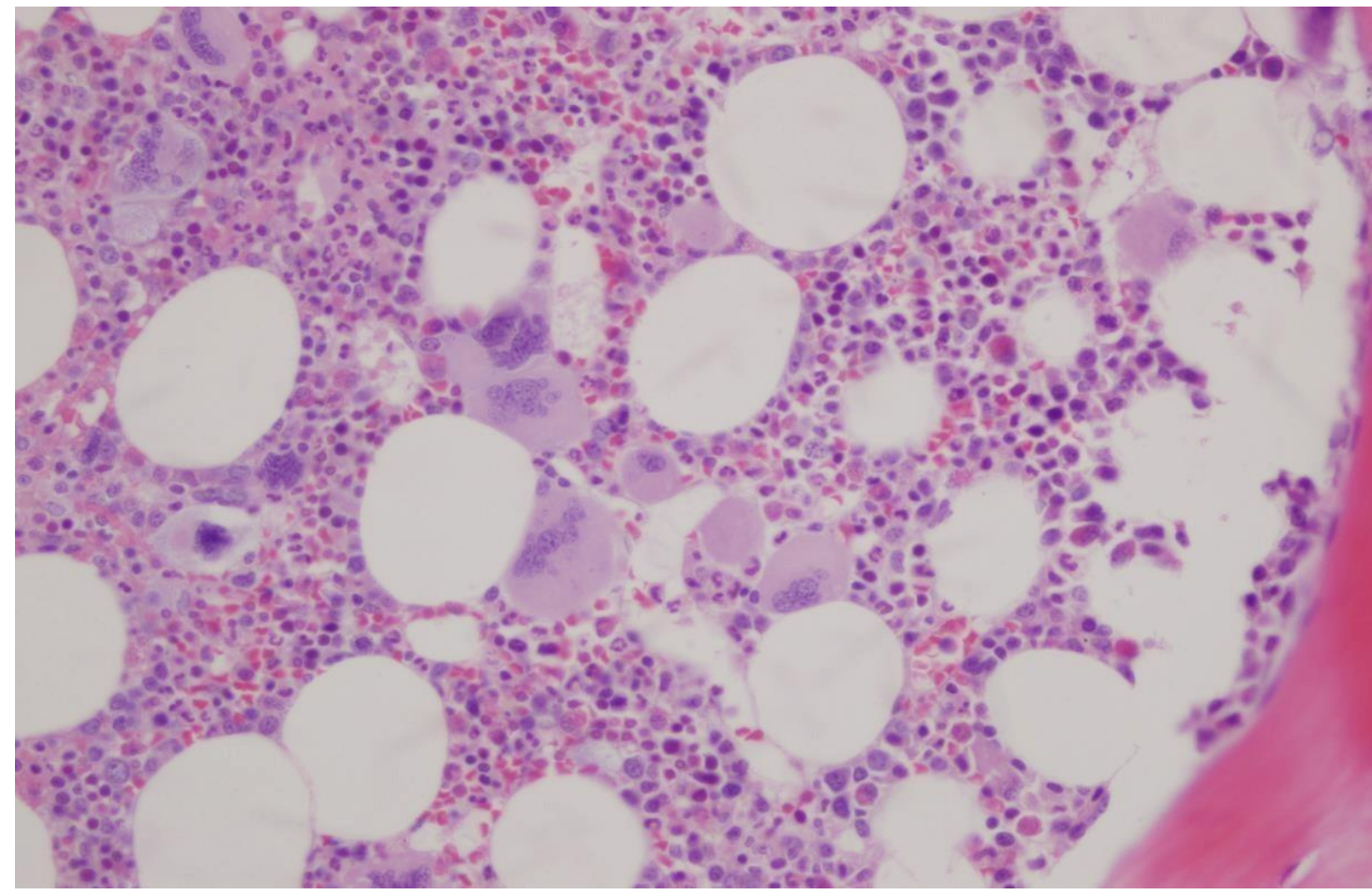

Figure 2: Increased megakaryocytes with hyperlobulated appearance in normocellular bone marrow in an essential thrombocytosis case (H\&E; x100). 


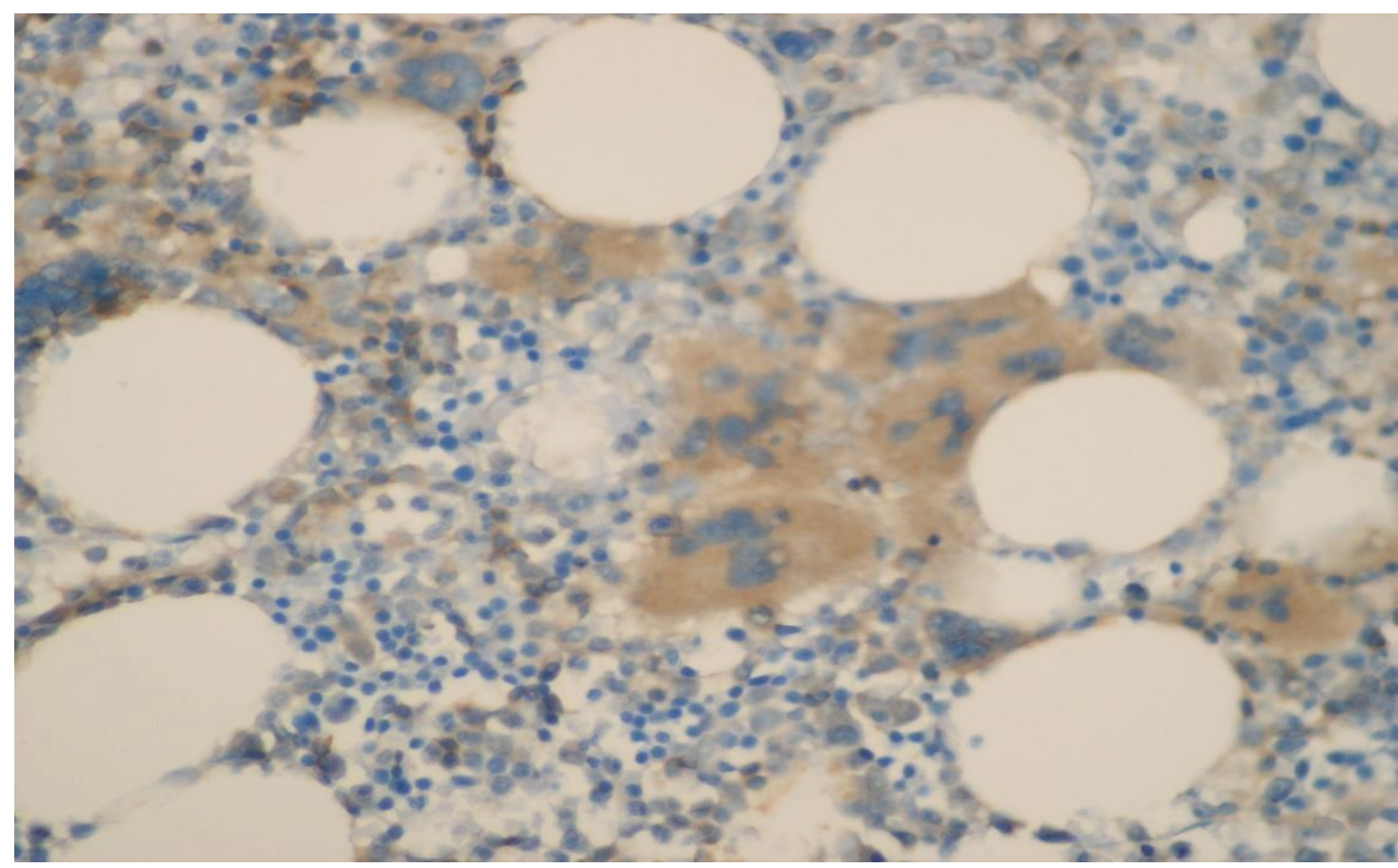

Figure 3: Cytoplasmic positivity with Wnt-1 in megakaryocytes in an essential thrombocytosis case (IHC; x200)

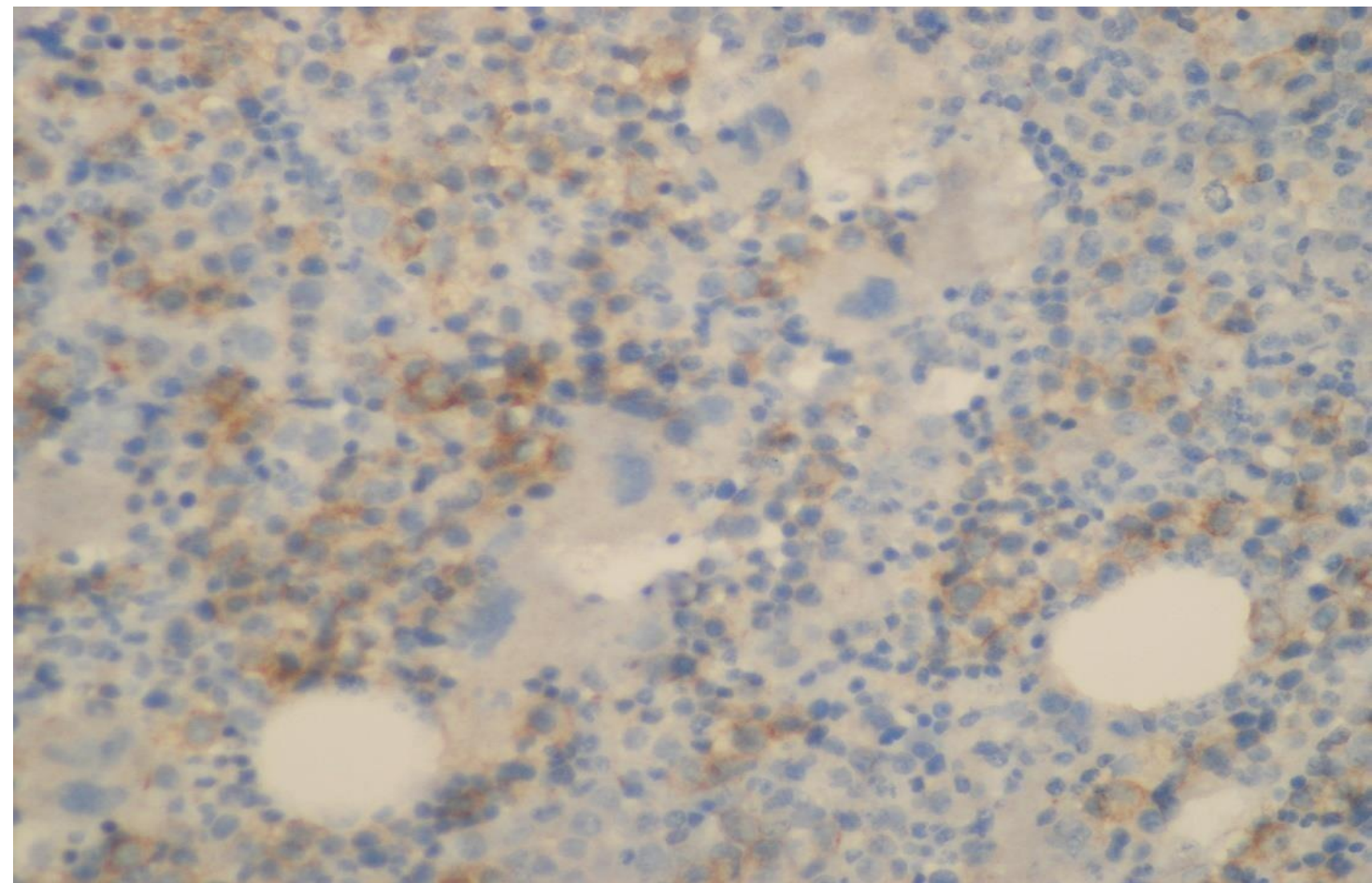

Figure 4: Membranous positive staining with E-cadherin in the erythroid series in an ET case (IHC; x200) 


\section{Discussion}

According to the World Health Organization (WHO) classification, myeloproliferative neoplasms (MPN) are divided into7 groups. PV and ET constitute two separate disease groups in this classification. PV is a disease that is characterized by excessed blood cells that increase independently of normal erythropoiesis mechanisms, while the increase in all three series in the bone marrow is note worthy. While an increase in platelets is prominent in an ET megakaryocyte increase is prominent in the bone marrow. It is known that the JAK-2 mutation has a diagnostic significance in both disease groups. However, the JAK-2 mutation is not helpful in reaching a differential diagnosis between PV and ET. It is known that both diseases have origins from hematopoietic stem cells (Shih and Lee 1994; Jantunen et al. 1999; Brière 2006; Thiele and Kvasnicka 2006; Swerdlow et al. 2008).

Different pathways take roles in the renewal and differentiation stages of hematopoietic stem cells. These pathways include the Wnt, SF/c-kit, Notch, HOX, EPO-induced signal pathways(Brandon et al. 2000; Tsiftsoglou et al. 2009). Although the effects of the Wnt signal pathway on the hematopoietic system are partially known, not many studies have been conducted in the literature for assessment of this pathway in the bone marrow in myeloproliferative neoplasms. In this study that we conducted to investigate the role of the Wnt signal pathway in the pathogenesis of ET and PV and whether or not it would be helpful in the differential diagnosis of these two diseases, we investigated the expressions of Wnt-1, $\beta$-catenin and E-cadherin that are found in the Wnt signal pathway in the bone marrow in ET and PV cases. In the analysis carried out by considering all three series (erythroid, myeloid, megakaryocytic) withWnt-1, positive results were obtained in the megakaryocytic series by $4 \%$ in the PV cases, $24 \%$ in the ET cases and $8 \%$ in the control group. When an intergroup analysis was conducted with these results, a significant difference in the megakaryocytic series was observed in the ET cases, and it was concluded that Wnt-1 has a role in megakaryocytopoiesis in ET cases. While there is no study in the literature which has investigated Wnt expression in myeloproliferative neoplasms, there are studies emphasizing the significance of the Wnt pathway in hematopoiesis and somenon-hematological tumor groups. Carlene et al. examined the effects of Wnt proteins on hematopoietic cells, and in the study they conducted in a culture medium (chicken and quailembryo), they determined that, when the suitable conditions were provided, normal hematopoiesis(erythrocyte, monocyte, macrophage and platelet) occurred in the bone marrow(Gumbiner 1996). Van den Berg et al. investigated the role of the Wnt gene family in hematopoiesis and reported that every Wnt receptor showed an effect by bondin with a different Wnt protein(Van Den Berg et al. 1998).Toshiyuli et al. emphasized that the targets of Wnt proteins are stromal proteins. Additionally, they reported that, other than Wnt, $\beta$-catenin is also effective in signal regulation (Yamane et al. 2001). Studies conducted on non-hematological cases have reported that Wnt pathway proteins take a role in the pathogenesis of phyllodes tumors of the breast, there is an increase in stromal nuclear $\beta$-catenin accumulation in a phyllodes tumor, and these pathways have a role in early tumor development and progression. It was reported that epithelial membranous and stromal nuclear $\beta$-catenin, epithelial cytoplasmic Wnt-1 and epithelial E-cadherin expression showed an increasing trend with an increasing degree of tumor, but the difference was not significant(Karim et al. 2009).Maria J. L. et al. stated that vitamin D receptor loss in colon tumors have a role in excessive activity in the Wnt/ $\beta$-catenin pathway, and in relation to this, speeding up the growth and malignancy of the tumor(Larriba et al. 2011). With $\beta$-catenin, no positive result was encountered in the ET, PV and control group cases. Monica $P$. et al. investigated the role of $\beta$-catenin in the pathogenesis of myeloproliferative neoplasms. In PV/ET cases, higher rates of cytoplasmic positive results were reported especially in megakaryocytes in comparison to chronic myeloid leukemia (CML)/ chronic idiopathic myelofibrosis (CIMF) series. The authors did not observe staining with $\beta$-catenin in the control group of normal bone marrows and explained these staining differences with morphological differences in megakaryocytes and stated that, while megakaryocytes are small, dysmorphic and hypolobulatedin CML, they are reflected in the morphology with a hyperlobulated appearance in CIMF, PV and ET. They reported that $\beta$-catenin positivity may provide benefits in distinguishing PV and ET from reactive processes. This conclusion was made by considering that, while $\beta$-catenin was positive in megakaryocytes in ET and PV cases, it was negative in the control group. Although there was strong cytoplasmic staining in PV and ET series with $\beta$-catenin in megakaryocytes, nuclear staining was not observed. The authors stated that nuclear staining is a more reliable finding that will reveal the activation of $\beta$-catenin and therefore the Wnt signal pathway(Jauregui et al. 2008) Serinsöz et al. determined that $\beta$-catenin showed cytoplasmic moderate/strong staining in megakaryocytes in myeloproliferative diseases withthe Philadelphia chromosome negativity (Serinsöz et al. 2004). In our study, as opposed to the data in the literature, negative results were obtained in all cases in the PV, ET

38 | $\mathrm{P}$ a g e 
and control groups. As the reasons that might have caused this difference, it was thought that the different primary antibody clone used in our study and the chemical agents we used for bone marrow decalcification may have reduced the antibody sensitivity. However, considering the positivity observed in the breast cancer tissue that we used as external control, it may also be concluded that $\beta$-catenin expression was actually not present. Additionally, studies to be conducted by increasing the numbers of cases and using different antibody clones may provide a contribution to this topic.

In their study conducted to investigate the role of $\beta$-catenin deficiency in lymphopoiesis and hematopoiesis, Monica C. et al. reported that T and B cell development was normal, and $\beta$-catenin deficiency was in significant in hematopoiesis, but they included the interpretation that it may be necessary to discuss the Wnt signal pathway in treatment-related processes in the hematopoietic system(Cobas et al. 2004). Studies conducted in non-hematological case groups have reported nuclear and/or cytoplasmic staining with $\beta$-catenin. Rakheja D. et al. determined that $33 \%$ of solitary fibrous tumors showed nuclear staining with $\beta$-catenin, while the rest showed cytoplasmic staining(Rakheja et al. 2005). Settakorn J.etal. determined that most of 31 intrahepatic cholangiocarcinoma cases showed granular cytoplasmic staining with $\beta$-catenin, while some showed membranous staining and others showed nuclear staining(Settakorn et al. 2005).Studies on myeloproliferative diseases have reported cytoplasmic staining (Serinsöz et al. 2004; Jauregui et al. 2008).

In our study, in the PV cases, a $4 \%$ positive result in the megakaryocytic series and $24 \%$ positive results in the erythroid series were observed with E-cadherin, while no staining was determined in the myeloid series. In the ET cases, while positivity was observed at a rate of $48 \%$ in the erythroid series, no positivity was observed in the megakaryocytic and myeloid series. In the control group, while there was a $4 \%$ positive result in the erythroid series, no positive result was observed in the megakaryocytic and myeloid series. When an intergroup analysis was conducted with these results, a significant difference was seen in the erythroid series in the ET cases and it was concluded that E-cadherin has a role in erythropoiesis in ET cases. While there is no study in the literature that has been conducted with Ecadherin in myeloproliferative neoplasms, studies covering leukemia cases reported an increase in the growth and transformation of leukemic cells by a decrease in the expression of E-cadherin(Rao et al. 2011). Zhonghua X.etal.showed tha tloss of E-cadherinin leukemic cells causes transcription and translocation activation of $\beta$-catenin in target genes(Rao et al. 2008). SubotickiT.et al. suggested that the Wnt/ $\beta$-catenin signaling pathway has a role in the angiogenesis of PMF and in the thrombopoiesis of PV andET. Hence, targeting the Wnt/ $\beta$-catenin signaling pathway could open new avenues for novel therapeutic approaches in bcr/abl-negative MPNs (Geduk et al. 2015). SubotickiT. et al. Our results indicat et hat $\beta$-catenin has different pattern of expression in different subtypes of MPNs. While in PV and ET patients Wnt/ $\beta$-catenin signaling pathway may have role in megakaryocytopoiesis, $\beta$-catenin may act as an angiogenic factorin PMF patients(Subotički et al. 2018).

In conclusion, our findings indicate that Wnt-1may be associated with megakaryopoesis in ET and Ecadherin with erythropoiesis in patients with ET. However, studies with larger patient population and evaluating other factors in the Wnt pathway for myeloproliferative neoplasms would be appropriate.

\section{References}

Austin TW, Solar GP, Ziegler FC, Liem L, Matthews W. 1997. A role for the Wnt gene family in hematopoiesis: expansion of multilineage progenitor cells. Blood, The Journal of the American Society of Hematology. 89(10):3624-3635.

Bloom W, Bartelmez G. 1940. Hematopoiesis in young human embryos. American Journal of Anatomy. 67(1):21-53.

Brandon C, Eisenberg LM, Eisenberg CA. 2000. WNT signaling modulates the diversification of hematopoietic cells. Blood, The Journal of the American Society of Hematology. 96(13):41324141 .

Budd-Chiari syndrome and portal vein thrombosis associated with myeloproliferative disorders: diagnosis and management. Seminars in thrombosis and hemostasis; 2006: Copyright $\odot 2006$ by Thieme Medical Publishers, Inc., 333 Seventh Avenue, New ....

39 | P a g e 
Cobas M, Wilson A, Ernst B, Mancini SJ, MacDonald HR, Kemler R, Radtke F. 2004. $\beta$-catenin is dispensable for hematopoiesis and lymphopoiesis. The Journal of experimental medicine. 199(2):221-229.

DALE CT. 1998. Signal transduction by the Wnt family of ligands. Biochemical Journal. 329(2):209-223.

Ding J, Komatsu H, Wakita A, Kato-Uranishi M, Ito M, Satoh A, Tsuboi K, Nitta M, Miyazaki H, Iida S. 2004. Familial essential thrombocythemia associated with a dominant-positive activating mutation of the c-MPL gene, which encodes for the receptor for thrombopoietin. Blood. 103(11):4198-4200.

Domen J, Weissman IL. 2000. Hematopoietic stem cells need two signals to prevent apoptosis; BCL-2 can provide one of these, Kitl/c-Kit signaling the other. Journal of Experimental Medicine. 192(12):1707-1718.

Geduk A, Atesoglu EB, Tarkun P, Mehtap O, Hacihanefioglu A, Demirsoy ET, Baydemir C. 2015. The role of $\beta$-catenin in $\mathrm{Bcr} / \mathrm{Abl}$ negative myeloproliferative neoplasms: an immunohistochemical study. Clinical Lymphoma Myeloma and Leukemia. 15(12):785-789.

Georgii A, Buesche G, Kreft A. 1998. 2 The histopathology of chronic myeloproliferative diseases. Baillière's clinical haematology. 11(4):721-749.

Gianelli U, Vener C, Raviele PR, Moro A, Savi F, Annaloro C, Somalvico F, Radaelli F, Franco V, Deliliers GL. 2006. Essential thrombocythemia or chronic idiopathic myelofibrosis? A singlecenter study based on hematopoieticbone marrow histology. Leukemia \& lymphoma. 47(9):1774-1781.

Update on diagnosis and management of essential thrombocythemia. Seminars in thrombosis and hemostasis; 2006: Copyright $(\mathcal{C} 2006$ by Thieme Medical Publishers, Inc., 333 Seventh Avenue, New ....

Gumbiner BM. 1996. Cell adhesion: the molecular basis of tissue architecture and morphogenesis. Cell. 84(3):345-357.

Jantunen R, Juvonen E, Ikkala E, Oksanen K, Anttila P, Ruutu T. 1999. Development of erythrocytosis in the course of essential thrombocythemia. Annals of hematology. 78(5):219222.

Jauregui MP, Sanchez SR, Ewton AA, Rice L, Perkins SL, Dunphy CH, Chang C-C. 2008. The role of $\beta$-catenin in chronic myeloproliferative disorders. Human pathology. 39(10):1454-1458.

Karim RZ, Gerega SK, Yang Y, Horvath L, Spillane A, Carmalt H, Scolyer RA, Lee CS. 2009. Proteins from the Wnt pathway are involved in the pathogenesis and progression of mammary phyllodes tumours. Journal of clinical pathology. 62(11):1016-1020.

Kralovics R, Passamonti F, Buser AS, Teo S-S, Tiedt R, Passweg JR, Tichelli A, Cazzola M, Skoda RC. 2005. A gain-of-function mutation of JAK2 in myeloproliferative disorders. New England Journal of Medicine. 352(17):1779-1790.

Larriba MJ, Ordonez-Moran P, Chicote I, Martin-Fernandez G, Puig I, Munoz A, Palmer HG. 2011. Vitamin D receptor deficiency enhances Wnt/ $\beta$-catenin signaling and tumor burden in colon cancer. PloS one. 6(8):e23524.

Levine RL, Wadleigh M, Cools J, Ebert BL, Wernig G, Huntly BJ, Boggon TJ, Wlodarska I, Clark JJ, Moore S. 2005. Activating mutation in the tyrosine kinase JAK2 in polycythemia vera, essential thrombocythemia, and myeloid metaplasia with myelofibrosis. Cancer cell. 7(4):387397. 
Diagnostic criteria and prognosis in polycythemia vera and essential thrombocythemia. Seminars in hematology; 1999.

Porwit A, McCullough J, Erber WN. 2011. Blood and bone marrow pathology e-book. Elsevier Health Sciences.

Rakheja D, Molberg KH, Roberts CA, Jaiswal VR. 2005. Immunohistochemical expression of $\beta$ catenin in solitary fibrous tumors. Archives of pathology \& laboratory medicine. 129(6):776779 .

Rao Q, Wang JY, Meng J, Tang K, Wang Y, Wang M, Xing H, Tian Z, Wang J. 2011. Low expression of $\mathrm{E}$ - cadherin in leukaemia cells causes loss of homophilic adhesion and promotes cell growth. Cell biology international. 35(9):945-951.

Rao Q, Xu Z-F, Wang J-Y, Meng J-H, Tang K-J, Tian Z, Xing H-Y, Wang M, Wang J-X. 2008. Leukemia cell surface expression of E-cadherin and its correlation with membrane localization of beta-catenin. Zhonghua xue ye xue za zhi= Zhonghua Xueyexue Zazhi. 29(9):592-594.

Serinsöz E, Neusch M, Büsche G, von Wasielewski R, Kreipe H, Bock O. 2004. Aberrant expression of $\beta$ - catenin discriminates acute myeloid leukaemia from acute lymphoblastic leukaemia. British journal of haematology. 126(3):313-319.

Settakorn J, Kaewpila N, Burns G, Leong AS. 2005. FAT, E-cadherin, $\beta$ catenin, HER 2/neu, Ki67 immunoexpression, and histological grade in intrahepatic cholangiocarcinoma. Journal of clinical pathology. 58(12):1249-1254.

Shih L-Y, Lee C-T. 1994. Identification of masked polycythemia vera from patients with idiopathic marked thrombocytosis by endogenous erythroid colony assay.

Subotički T, Mitrović Ajtić O, Mićić M, Kravić Stevović T, Đikić D, Diklić M, Leković D, Gotić M, Čokić VP. 2018. $\beta$-catenin and PPAR- $\gamma$ levels in bone marrow of myeloproliferative neoplasm: an immunohistochemical and ultrastructural study. Ultrastructural pathology. 42(6):498-507.

Swerdlow SH, Campo E, Harris NL, Jaffe ES, Pileri SA, Stein H, Thiele J, Vardiman JW. 2008. WHO classification of tumours of haematopoietic and lymphoid tissues. Vol. 2. International agency for research on cancer Lyon, France.

Clinicopathological criteria for differential diagnosis of thrombocythemias in various myeloproliferative disorders. Seminars in thrombosis and hemostasis; 2006: Copyright(C 2006 by Thieme Medical Publishers, Inc., 333 Seventh Avenue, New ....

Tsiftsoglou AS, Bonovolias ID, Tsiftsoglou SA. 2009. Multilevel targeting of hematopoietic stem cell self-renewal, differentiation and apoptosis for leukemia therapy. Pharmacology \& therapeutics. 122(3):264-280.

Van Den Berg DJ, Sharma AK, Bruno E, Hoffman R. 1998. Role of members of the Wnt gene family in human hematopoiesis. Blood, The Journal of the American Society of Hematology. 92(9):3189-3202.

Yamane T, Kunisada T, Tsukamoto H, Yamazaki H, Niwa H, Takada S, Hayashi S-I. 2001. Wnt signaling regulates hemopoiesis through stromal cells. The Journal of Immunology. 167(2):765772 . 